\title{
UTILIZAÇÃO DE CONSERVANTE PARA ESTABILIZAÇÃO DO BIOSSURFACTANTE PRODUZIDO POR Candida guilliermondii EM BIORREATOR
}

\author{
P. P. F. BRASILEIRO ${ }^{1,2}$, H. S. AMORIM ${ }^{1}$, B. G. de FREITAS ${ }^{1}$, A. H. M. RESENDE ${ }^{1}$, D. G. de \\ ALMEIDA $^{1,2}$, J. M. de LUNA ${ }^{1,2}$, R. D. RUFINO ${ }^{1,2}$, L. A. SARUBBO ${ }^{1,2}$ e V. A. dos SANTOS ${ }^{1,2}$ \\ ${ }^{1}$ Universidade Católica de Pernambuco (UNICAP), Centro de Ciências e Tecnologia (CCT) \\ ${ }^{2}$ Centro de Gestão de Tecnologia e Inovação (CGTI) \\ E-mail para contato: ppfbrasileiro@ hotmail.com
}

\begin{abstract}
RESUMO - O derramamento de petroderivados é letal à biota marinha, necessitando de práticas sustentáveis para o controle desse desastre ambiental. Nesse sentido, pesquisas estão sendo desenvolvidas para a fermentação de resíduos industriais a fim de sintetizar os biossurfactantes: os biorremediadores do petróleo. O trabalho, porquanto, buscou verificar, no tensoativo obtido pela levedura Candida guilliermondii, a estabilidade das propriedades surfactantes pelo uso de sorbato de potássio $(0,2 \%)$. O meio fermentado em biorreator $(50 \mathrm{~L})$ com 4,0\% de milhocina, 2,5\% de melaço e 2,5\% de óleo de soja foi submetido, então, a variações de $\mathrm{pH}$, temperatura e aquecimento durante 120 dias. Após o período, foram constatadas: mínima tensão superficial de $29,51 \mathrm{mN} / \mathrm{m}$, emulsões de $100,0 \%$, dispersão máxima de $76,8 \%$ e as melhores condições de $\mathrm{pH} 8$, aquecimento a 50 ${ }^{\circ} \mathrm{C}$ ou salinidade 1 ou $5 \%$. O biossurfactante produzido por C. guilliermondii, logo, é viável para o controle de petroderivados em água do mar.
\end{abstract}

\section{INTRODUÇÃO}

Energia é uma palavra cujo conceito é complexo diante das distintas origens das quais pode ser obtida, outrossim, das variadas aplicabilidades. Dentre uma das procedências, a energia química é estudada por pesquisas referentes ao refino e à utilização do petróleo, pois a mistura de hidrocarbonetos é uma fonte rentável para os industriais, os quais necessitam de lucros crescentes para a manutenção das empresas no mercado de trabalho (FAHIM et al., 2012). Essa competitividade comumente exclui o foco na preservação da natureza, ameaçando ecossistemas com a contaminação de áreas pelo petróleo. O despejo de compostos petroderivados em ambientes marinhos, portanto, é frequente e não há ainda produtos comercializáveis para a degradação desses poluentes em cerca de 24 horas, bem como, para o controle das grandes manchas de petróleo sem o acúmulo de agentes tóxicos na biota marinha (MARTI et al., 2014).

No dia 10 de abril de 2010, a explosão da plataforma de perfuração Deepwater Horizon (DWH) causou o derramamento de 780 milhões de litros de petróleo até o dia 15 de junho de 2010, quando 


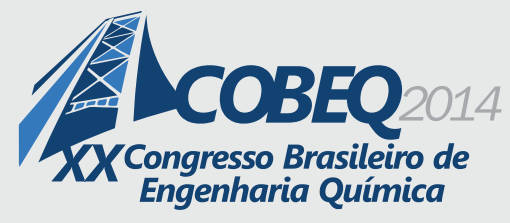

19 a 22 de outubro de 2014
Florianópolis/SC

finalmente a ruptura da fonte de sucção foi fechada. A mistura de hidrocarbonetos, durante o desastre, necessitava ser retirada do oceano, pois uma majoritária fração encontrava-se submersa, impossibilitando uma acessível captação dos óleos e intoxicando a biota marinha existente. Como tentativa de solucionar o imbróglio, cientistas utilizaram dispersantes químicos para poderem recuperar o petróleo com maior facilidade, porém a origem petroderivada desses compostos, também denominados de surfactantes, acumulou a toxicidade no ambiente, refletindo, porquanto, uma inviável remediação (ZHOU et al., 2013).

No intuito de manter a utilização de compostos que se agreguem a substâncias hidrofóbicas e hidrofílicas simultaneamente, pesquisas estão sendo desenvolvidas com a finalidade de sintetizar dispersantes com menor toxicidade, maior biodegradabilidade, mínimos custos de produção e elevada estabilidade frente às condições do ambiente. Esses surfactantes são obtidos a partir do inóculo de micro-organismos com potencial biotecnológico em meios de produção provenientes de resíduos industriais, formando os biossurfactantes (ROCHA e SILVA et al., 2014).

As aplicações de quaisquer dispersantes químicos ou microbianos dependem principalmente das mínimas tensões superficial e interfacial apresentadas. Aquela se caracteriza pelo grau de espalhamento ou umectação, pois ao atingir uma maior superfície de contato, aumenta o número de interações intermoleculares; enquanto que esta indica a penetrabilidade do surfactante em compostos apolares, facilitando, em derramamentos, a redução das forças repulsivas entre os compostos imiscíveis. Logo, nos desastres petrolíferos, os fenômenos usuais como emulsões e dispersões, pela ação dos biossurfactantes, precisam demonstrar propriedades tensoativas similares ou superiores aos dos surfactantes químicos para evitar a maior contaminação do ambiente marinho com semelhante qualidade de atuação (DALTIN, 2011).

A Termopernambuco é uma das empresas que se preocupa com acidentes petrolíferos por localizar-se no Complexo Portuário de Suape, onde há riscos de ocorrerem derramamentos, os quais podem obstruir o sistema de captação de água do mar, utilizado para arrefecer os geradores da empresa. No momento desse desastre ambiental, não haveria a possibilidade de se realizar uma fermentação de 144 horas para a síntese de um surfactante microbiano, portanto, é essencial a manutenção das propriedades tensoativas durante um longo período. A adição de conservantes como o sorbato de potássio, pois, é uma alternativa em potencial para o uso em produtos microbiológicos, preservando as características fundamentais para a imediata aplicação.

O trabalho buscou investigar, então, a estabilidade do biossurfactante sintetizado pela levedura Candida guilliermondii, em biorreator do tipo batelada, com o conservante sorbato de potássio $(0,2 \%)$ pela determinação da tensão superficial e dos índices de emulsificação e de dispersão nos tempos de 0, 15, 30, 45, 90 e 120 dias. Em cada período, foram variadas as condições de potencial hidrogeniônico, salinidade e aquecimento, mantendo-se também amostras com o controle do surfactante com o sorbato. As melhores condições de aplicação, pois, foram estabelecidas ao final dos períodos de análise. 


\section{9 a 22 de outubro de 2014 \\ Florianópolis/SC}

\section{MATERIAL E MÉTODOS}

\subsection{Micro-organismo e Substratos}

A levedura Candida guilliermondii (UCP0992), depositada no Banco de Culturas do Núcleo de Pesquisas Ambientais da Universidade Católica de Pernambuco foi utilizada como produtora do biossurfactante. A repicagem desse organismo microbiano ocorreu, a cada 30 dias, para tubos de ensaio contendo o meio sólido de Yeast Mold Agar (YMA). Como fontes de energia, para a produção do biossurfactante, foram utilizados a milhocina, o melaço e o óleo de soja residual (SANTOS et al., 2013).

\subsection{Meios de Manutenção, de Crescimento do Inóculo e de Produção do Biossurfactante}

A levedura foi mantida através da mistura sólida de YMA, composta por: extrato de malte $(0,3 \%)$, extrato de levedura $(0,3 \%)$, D-glicose $(1,0 \%)$, triptona $(0,5 \%)$, ágar bacteriano $(2,0 \%)$ e água destilada q.s.p. $(100 \mathrm{~mL})$, sendo os componentes esterilizados em autoclave a $121{ }^{\circ} \mathrm{C}$ por $20 \mathrm{~min}$. A exclusão do ágar propicia à mistura o estado líquido e é denominada de Yeast Mold Broth (YMB), indicando o meio de crescimento da levedura. $\mathrm{O}$ meio de produção foi composto pelo acréscimo de $4,0 \%$ de milhocina e $2,5 \%$ de melaço do volume inicial, o $\mathrm{pH}$ foi ajustado para 5,5, acrescentou-se $2,5 \%$ de resíduo de óleo de soja e todo o meio foi autoclavado a $121{ }^{\circ} \mathrm{C}$ por $20 \mathrm{~min}$ (RUFINO et al., 2014).

\subsection{Preparação do Inóculo}

O inóculo tornou-se padrão pela transferência da $C$. guilliermondii para um tubo de ensaio, contendo o meio YMA, com a finalidade de se obter uma cultura jovem, em temperatura ambiente $\left(25{ }^{\circ} \mathrm{C}\right)$. Logo após, as leveduras foram transferidas assepticamente até um frasco com YMB estéril. Por fim, o Erlenmeyer com YMB foi posto à agitação na máquina incubadora shaker durante 24 horas, a $200 \mathrm{rpm}$ e a $28^{\circ} \mathrm{C}$.

\subsection{Produção do Biossurfactante}

Após o crescimento do inóculo em meio YMB, a síntese do biossurfactante em biorreator de batelada com $50 \mathrm{~L}$ de capacidade volumétrica, conforme a figura 1, foi realizada por uma diluição seriada para a contagem das células por mililitro, na figura 2, calculando-se o volume para alcançar a concentração de $10^{4}$ células $/ \mathrm{mL}$. Essa quantidade foi inserida em $20 \mathrm{~L}$ do meio de produção, selecionado em shaker, estéril, sob agitação mecânica de $90 \mathrm{rpm}$, durante 144 horas e sob temperatura de $28{ }^{\circ} \mathrm{C}$, a qual era controlada por um banho termostatizado. Ademais, o reator biológico apresentava dois impelidores do tipo turbina de disco com lâminas verticais retas, separadas por uma haste de 15 $\mathrm{cm}$, e chicanas para melhor homogeneizar o meio de produção. 


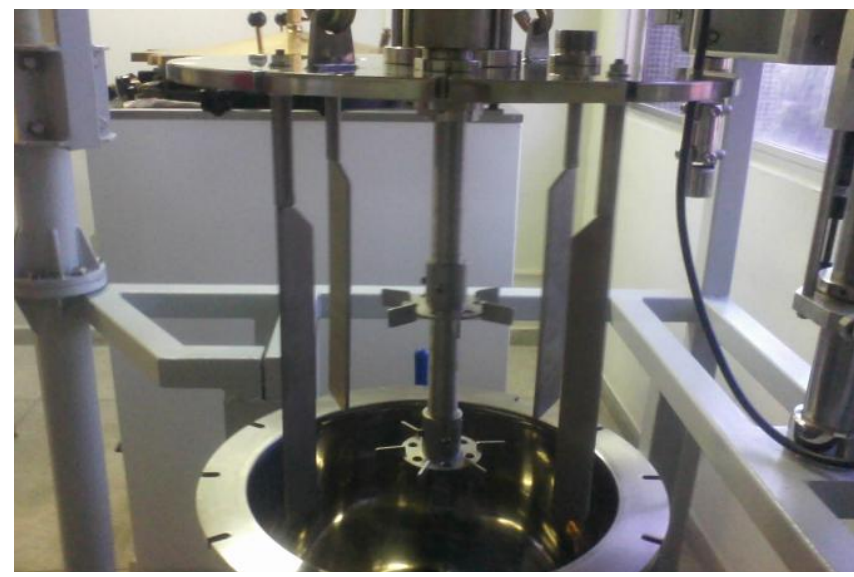

Figura 1 - Cuba do biorreator de 50 L com os impelidores do tipo turbina de disco com lâminas verticais retas e chicanas.

A

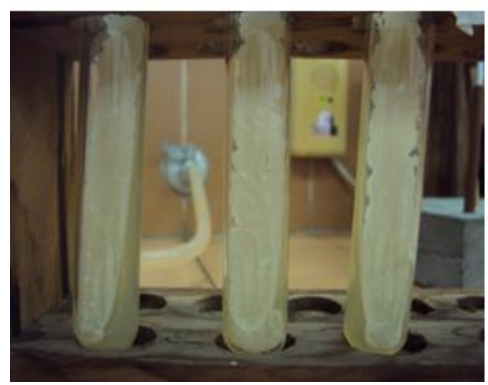

B

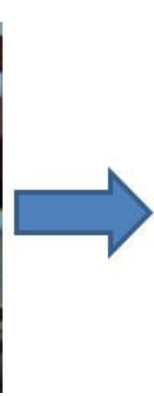

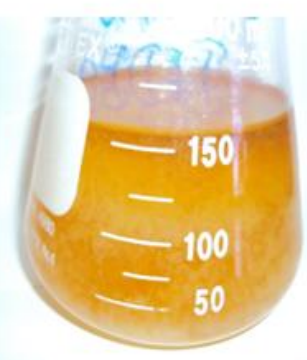

C

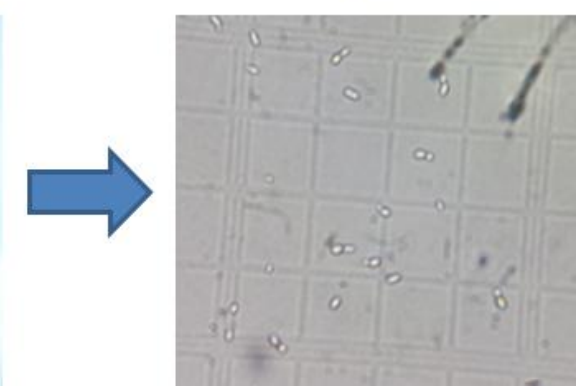

Figura 2 - Etapas de contagem das células microbianas a partir de (A) um meio sólido para (B) um meio líquido, verificando-se a (C) concentração celular.

\subsection{Estabilização do Biotensoativo e Determinação das Propriedades Surfactantes}

O líquido metabólico obtido pelo biorreator foi centrifugado a $4500 \mathrm{rpm}$ durante 15 min e filtrado à vácuo, para a retirada das células. $\mathrm{O}$ biossurfactante também passou por uma filtração simples devido à baixa agitação oferecida pela máquina piloto industrial no momento da produção do biossurfactante.

A estabilização do surfactante microbiano ocorreu quando $0,2 \%$ do sal sorbato de potássio foi adicionado e o líquido foi dividido em vidros de armazenamento, em triplicata, para a verificação das propriedades surfactantes nos períodos de 0, 15, 30, 45, 90 e 120 dias. Em cada um desses dias, foram alteradas, separadamente, as condições de potencial hidrogeniônico para 6, 8 e 10; adicionadas percentagens de $\mathrm{NaCl}$ a 1,3 e $5 \%$ do volume a ser estudado e aquecidas as amostras durante $30 \mathrm{~min}$ a 40 e $50{ }^{\circ} \mathrm{C}$. Para avaliar as propriedades surfactantes, foram mensuradas as melhores médias de cada condição nas tensões superficiais e nos índices de emulsificação e de dispersão.

As tensões superficiais foram medidas pelo método do anel DU NUOY no tensiômetro KSV Sigma 70 (Finland), determinando-se a força limite $(\mathrm{mN} / \mathrm{m})$ para suspender o anel de platina sobre o 


\section{9 a 22 de outubro de 2014 \\ Florianópolis/SC}

líquido metabólico livre de células até a interface ar-líquido.

Para a determinação das emulsões, foram colocados em tubos de ensaio, $2 \mathrm{~mL}$ do biossurfactante acoplados isovolumetricamente a três compostos apolares: óleos motor, de milho e de soja a $25{ }^{\circ} \mathrm{C}$ e 1 atm. Esses recipientes foram agitados em vórtex durante 2 minutos e deixados, durante 24 horas, em repouso. $O$ índice de emulsificação foi calculado pela razão entre a altura da emulsão e a altura total da mistura, sendo o valor multiplicado por 100 (COOPER e GOLDENBERG, 1987).

A capacidade de dispersão do óleo motor foi simulada em placa de Petri (14 cm de diâmetro), contendo $100 \mathrm{~mL}$ da água do mar, coletada nas proximidades do sistema de captação do gerador de energia da Termelétrica de Pernambuco. Uma quantidade desse óleo foi colocada no centro da placa, adicionando posteriormente diferentes proporções (v/v) do surfactante microbiano de 1:1, 1:2 e 1:8 (biossurfactante/óleo motor). Os valores foram medidos pela percentagem do diâmetro do halo formado com a adição do biossurfactante pelo da placa (MORIKAWA et al., 2000).

\section{RESULTADOS E DISCUSSÕES}

\subsection{Estabilidade do Biossurfactante pela Tensão Superficial}

A inclusão do sorbato no tensoativo causou um aumento inicial em todas as tensões superficiais, como visualizado na figura 3 , destacando-se uma maior variação de $5,17 \mathrm{mN} / \mathrm{m}$ na salinidade $1 \%$, quando as médias das amostras foram comparadas com o controle do biossurfactante bruto.

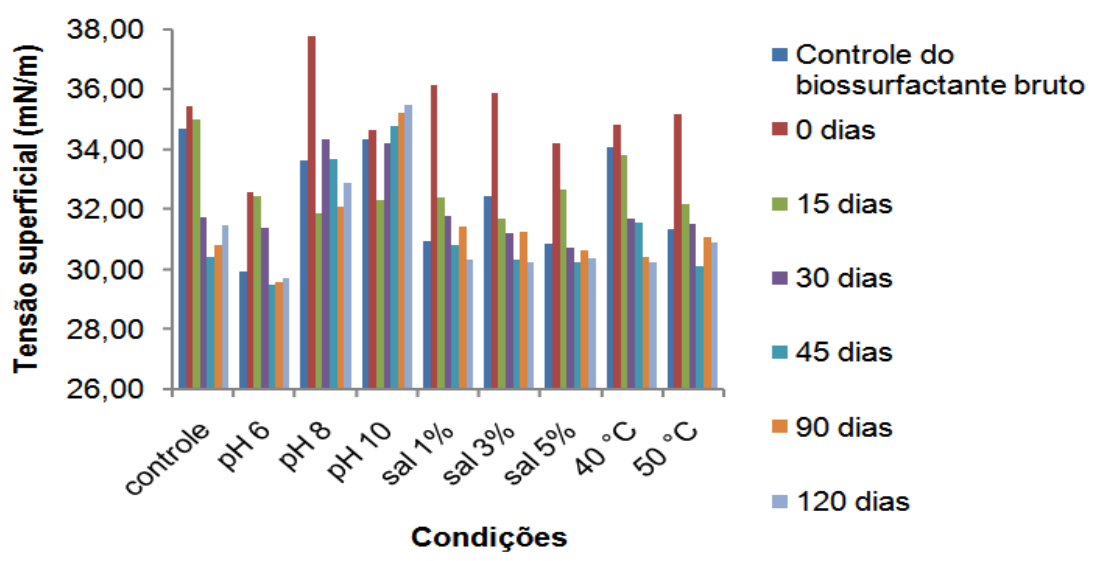

Figura 3 - Tensões superficiais do biossurfactante do biorreator com sorbato a 0,2\%, durante 120 dias, sob variação de $\mathrm{pH}, \mathrm{NaCl}$, aquecimento e com o controle das condições.

Nos 15 dias de experimento, no entanto, as tensões dos surfactantes com sorbato começaram a se aproximar das forças repulsivas apresentadas nos controles do bioproduto, sem conservante, e até sendo menores, como verificadas nos potenciais 8 e 10, na salinidade $3 \%$ e no aquecimento sob 40 ${ }^{\circ} \mathrm{C}$. A partir dos 30 até os 120 dias, houve uma maior estabilidade das tensões superficiais em todas as condições, ratificando a aplicação do sorbato de potássio para manter o biossurfactante produzido por C. guilliermondii estável. 
As melhores condições foram obtidas em $\mathrm{pH} 6$, salinidade $5 \%$ e aquecimento a $50{ }^{\circ} \mathrm{C}$, com as respectivas e menores tensões superficiais de 29,51;30,26 e 30,13 mN/m. Com esses dados, o método de conservação superou o prazo estimado para delimitar uma validade ao biossurfactante, reduzindo as tensões superficiais em vez de apenas mantê-las. Ademais, é importante salientar que antes dos primeiros 15 dias de conservação deve-se preferir aplicar o biossurfactante sem sorbato em um derramamento de petróleo.

\subsection{Estabilidade do Biossurfactante pelos Índices de Emulsificação}

Nos índices de emulsificação em óleo motor, figura 4-A, foram percebidas severas reduções, quando o $\mathrm{pH}$ foi aumentado diante do controle do biossurfactante, refletindo índices em cerca de $50,0 \%$. Esse acontecimento foi de encontro ao ocorrido nas figuras 4-B, com óleo de soja, e 4-C, com óleo de milho, pois um potencial 10 elevou a emulsificação a 92,1\% no óleo de soja.

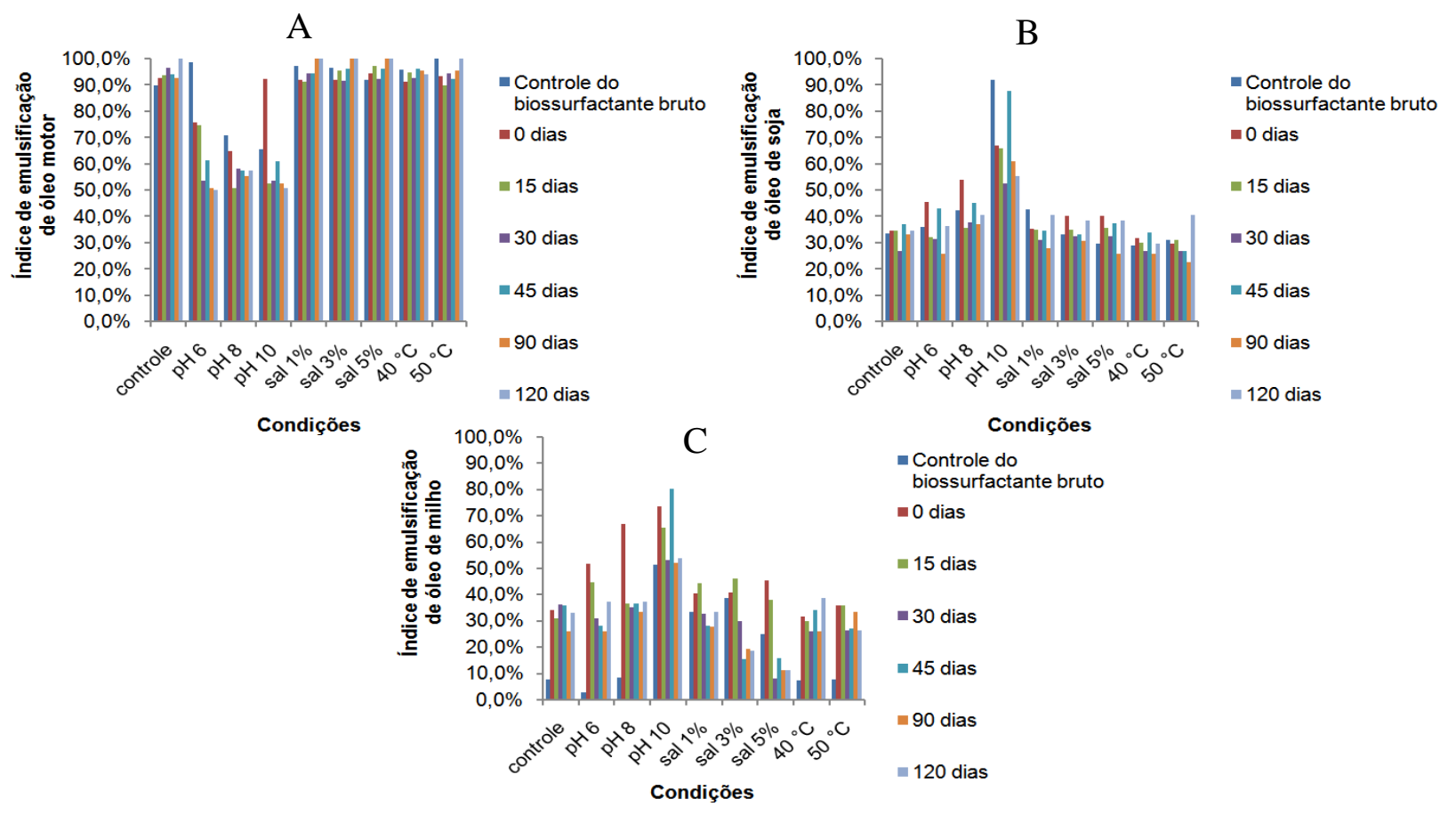

Figura 4 - Índices de emulsificação do biossurfactante do biorreator com sorbato a 0,2\%, durante 120 dias, sob variação de $\mathrm{pH}, \mathrm{NaCl}$, aquecimento e com controle das condições, nos óleos: (A) motor, (B) de soja e (C) de milho.

Os melhores resultados foram nas emulsificações do óleo motor com oito índices máximos $(100,0 \%)$ e determinação das condições mais viáveis com pH 6, salinidade 5\% e aquecimento a 50 ${ }^{\circ} \mathrm{C}$. As emulsificações nos óleos de soja e de milho foram bastante semelhantes, outrossim, apresentaram as mais efetivas condições em $\mathrm{pH} 10$, aquecimento a $40{ }^{\circ} \mathrm{C}$ e salinidade de 3 e $1 \%$, respectivamente. 


\section{9 a 22 de outubro de 2014 \\ Florianópolis/SC}

\subsection{Estabilidade do Biossurfactante pelos Índices de Dispersão}

Os percentuais das dispersões, explicitados na figura 5, foram elevados apenas frente às alterações de $\mathrm{pH}$ e apresentaram um valor máximo de 76,8\% nos primeiros testes realizados em $\mathrm{pH} 8$ e na proporção 1:1 (v/v) de biossurfactante para óleo motor. As melhores condições observadas nos índices de 1:1, 1:2 e 1:8 indicaram o pH 8 em todas as proporções, as salinidades em 5, 1 e 1\%, nessa ordem, e o aquecimento em 40,50 e $50{ }^{\circ} \mathrm{C}$ para as respectivas proporções. Ademais, deve-se salientar a subtração do tamanho das dispersões com o aumento da quantidade de óleo inserida.

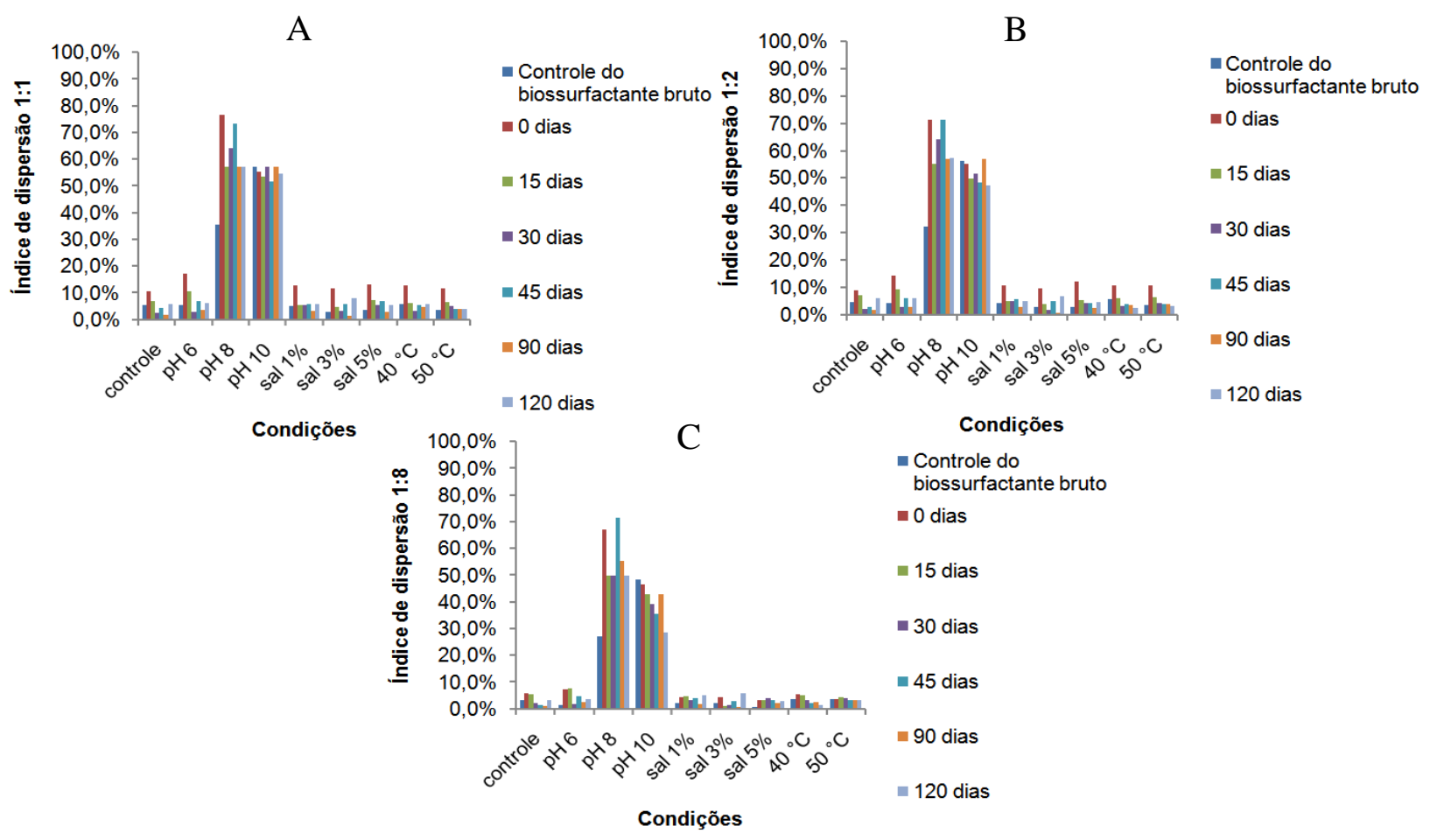

Figura 5 - Índices de dispersões do biossurfactante do biorreator com sorbato a 0,2\%, durante 120 dias, sob variação de $\mathrm{pH}, \mathrm{NaCl}$, aquecimento e com o controle, nas proporções de biossurfactante/óleo (v/v): (A) 1:1, (B) 1:2 e (C) 1:8.

\section{CONCLUSÕES}

O somatório das melhores condições para o biossurfactante produzido em biorreator piloto industrial sugerem, portanto, que o potencial hidrogeniônico 8 , o aquecimento a $50{ }^{\circ} \mathrm{C}$ ou as salinidades 1 ou 5\% devem ser aplicadas isoladamente antes de efetuar a biorremediação cujas medidas de $\mathrm{pH}$ e $\mathrm{NaCl}$ apresentam um teor semelhante ao dos oceanos. Deve-se também enaltecer que se as condições foram visualizadas separadamente, faz-se necessário um estudo em arranjo para perceber os sinergismos e os antagonismos da mistura entre o $\mathrm{pH}$, o aquecimento e a salinidade.

As propriedades surfactantes da tensão superficial e da emulsificação apresentaram uma ótima 
qualidade para uma maior umectação e penetrabilidade do líquido metabólico em compostos hidrofóbicos, garantindo, com o auxílio das correntes marinhas, um amplo contato entre o agente tensoativo e o contaminante. As dispersões, todavia, foram efetivas apenas em potenciais 8 ou 10 .

O campo dos biossurfactantes sugere uma alternativa para remediar os grandes derramamentos, os quais acumulam uma enorme quantidade de poluentes letais aos organismos marinhos, principalmente, quando há um processo fermentativo com o meio composto por $100 \%$ de resíduos industriais. Esses rejeitos acoplados ao potencial biotecnológico da levedura Candida guilliermondii e à estabilidade proporcionada pelo sorbato de potássio, em mínimas concentrações, torna o uso desse bioproduto, no mínimo, um objeto de estudo para ser aprimorado e aplicado em desastres ambientais.

\section{REFERÊNCIAS}

COOPER, D. G.; GOLDENBERG, B. G. Surface-Active Agents from two Bacillus Species. Appl. Environ. Microbiol., v. 53, p. 224-229, 1987.

DALTIN, D. Tensoativos: química, propriedades e aplicações. São Paulo: Editora Blucher, 2011.

FAHIM, M. A.; AL-SAHHAF, T. A.; ELKILANI, A. S. Introdução ao Refino de Petróleo. Rio de Janeiro: Editora Campus, 2012.

MARTI, M. E.; COLONNA, W. J.; PATRA, P.; ZHANG, H.; GREEN, C.; REZNIK, G.; PYNN, M.; JARRELL, K.; NYMAN, J. A.; SOMASUNDARAN, P.; GLATZ, C. E., LAMSAL, B. P. Production and characterization of microbial biosurfactants for potential use in oil-spill remediation. Enzyme Microb. Technol., v. 55, p. 31-39, 2014.

MORIKAWA, M.; HIRATA, Y.; IMANAKA, T. A study on the structure-function relationship of lipopeptide biosurfactants. Biochim. Biophys. Acta, v. 1488, p. 211-218, 2000.

ROCHA e SILVA, N. M. P.; RUFINO, R. D.; LUNA, J. M.; SANTOS, V. A.; SARUBBO, L. A. Screening of Pseudomonas species for biosurfactant production using low-cost substrates. Biocatal. Agric. Biotechnol., v. 3, p. 132-139, 2014.

RUFINO, R. D.; LUNA, J. M.; CAMPOS TAKAKI, G. M.; SARUBBO, L. A. Characterization and properties of the biosurfactant produced by Candida lipolytica UCP 0988. Electron. J. Biotechno., v. 17, p. 34-38, 2014.

SANTOS, D. K. F.; RUFINO, R. D.; LUNA, J. M.; SANTOS, V. A.; SAlGUEIRO, A. A.; SARUBBO, L. A. Synthesis and evaluation of biosurfactant produced by Candida lipolytica using animal fat and corn steep liquor. J. Petrol. Sci. Eng., v. 105, p. 43-50, 2013.

ZHOU, Z.; GUO, L.; SHILlER, A. M.; LOHRENZ, S. E.; ASPER, V. L.; OSBURN, C. L. Characterization of oil components from the Deepwater Horizon oil spill in the Gulf of Mexico using fluorescence EEM and PARAFAC techniques. Mar. chem., v. 148, p. 10-21, 2014. 